\title{
DETERMINAÇ̃̃O DO ÍNDICE DE ESTADO TRÓFICO PARA FÓSFORO EM PONTOS DO RIO POMBA
}

José de Alencar Pinto Farage ${ }^{1}$, Antonio Teixeira de Matos $^{2}$, Demetrius David da Silva ${ }^{3}$, Alisson Carraro Borges ${ }^{4}$

\section{RESUMO}

Para avaliação do grau de trofia do curso de água calculado o índice de estado trófico para fósforo (IETpt) em nove diferentes pontos do Rio Pomba, Estado de Minas Gerais, durante os períodos de estiagem e de chuva. Os valores do IETpt foram obtidos por meio da equação proposta por CARLSON (1977) modificada por TOLEDO Jr. (1990). O maior aporte de fósforo total no curso de água foi verificado nos trechos em que o Rio Pomba é receptor de grande carga de efluentes domésticos e industriais e de fertilizantes fosfatados utilizados em áreas de cultivo agrícola. De acordo com o resultados, observou-se que, no período de estiagem, o Rio Pomba encontrava-se parcialmente eutrofizado, enquanto no período chuvoso, todo o percurso avaliado apresentou estado eutrófico, com a faixa de variação do IETpt predominando entre 54 e 74. Os resultados indicaram que o processo de lavagem superficial em áreas antropizadas que foi maior no período chuvoso, proporcionou maior carga de fósforo ao rio, aumentando sua concentração, mesmo com incrementos na vazão do curso de água.

Palavras-chave: eutroficação, índice de estado trófico, qualidade de água.

\section{ABSTRACT \\ DETERMINATION OF TROPHIC STATE INDEX FOR PHOSPHORUS AT DIFFERENT POINTS OF THE RIVER POMBA}

To assess the calculated trophic state of the watercourse, the trophic state index (TSI) of the River Pomba, Minas Gerais, was determined during dry and rainy period. The water samples were collected from nine different points of the river. The TSI values were calculated by replacing the variable by the total phosphorus in the equation proposed by CARLSON (1977) and modified by TOLEDO Jr. (1990). The maximum concentration of P was found in sectors where the River Pomba received domestic and industrial effluents, and phosphate fertilizers used in agricultural areas. The data revealed that during the dry period, the River Pomba was partially eutrophic, while in the rainy season, the entire evaluated route was characterized as eutrophic, with a TSI varying predominantly between 54 and 74 . The results indicated that the surface washing of anthropic surface areas was higher during rainy season, which most contributed to the phosphorus load in the river, thus increasing its concentration even with increased flow of the watercourse.

Keywords: eutrophication, trophic state index, water quality

\section{Recebido para publicação em 26/01/2009. Aprovado em 11/01/2010}

1- Engenheiro Agrícola, Professor da UNIPAC - Campus V - Leopoldina, e-mail: alencar.farage@yahoo.com.br

2- Engenheiro Agrícola, Professor do Departamento de Engenharia Agrícola/UFV, e-mail: atmatos@ufv.br;

3- Eng. Agrônomo, Professor do Departamento de Engenharia Agrícola/UFV, e-mail: david@ufv.br;

4- Engenheiro Civil, Professor do Departamento de Engenharia Agrícola/UFV, e-mail: borges@ufv.br. 


\section{INTRODUÇÃO}

Quando a disponibilidade e, principalmente, a qualidade da água encontram-se comprometidas, esta pode causar transtornos ao bem-estar da população e, inclusive, contribuir para o surgimento de doenças de veiculação hídrica. Com isso, a flora e a fauna, a depender da carga poluidora, podem ser afetadas.

O carreamento de parte dos fertilizantes utilizados em culturas agrícolas e a grande carga de efluentes residenciais e industriais têm levado corpos hídricos a uma condição de desequilíbrio, em termos de disponibilidade de nutrientes. Quando em concentrações superiores àquelas consideradas como normal nos meios aquáticos, os nutrientes podem provocar mudanças em suas características, podendo afetar os diversos usos da água, os quais vão desde a preservação das vidas aquáticas até o consumo humano, fenômeno este, conhecido como eutroficação antrópica.

A eutroficação é caracterizada pelo aumento na concentração de nutrientes, especialmente fósforo e nitrogênio, nos ecossistemas aquáticos, acarretando problemas como estímulo ao crescimento excessivo de algas, aumento da taxa de decomposição da matéria orgânica, com a redução do oxigênio dissolvido, e conseqüentemente, a deterioração da qualidade da água (ESTEVES, 1988; CAVENAGHI, 2003).

$\mathrm{O}$ uso da água no abastecimento humano, agricultura, pecuária, indústria e agroindústria, extração mineral e na diluição de efluentes domésticos, industriais e agroindustriais é indicativo da grande importância da bacia hidrográfica do Rio Pomba para a região, onde estão inseridos trinta e cinco municípios mineiros e três municípios fluminenses, abrigando uma população aproximada de 600 mil habitantes. Em vista dos múltiplos usos que essas águas estão sujeitas, faz-se necessário o conhecimento de sua qualidade e quantidade, de modo que haja uma gestão eficiente e criteriosa dos recursos hídricos disponíveis.

Segundo Esteves(1988), o fosfato presente em ecossistemas aquáticos continentais tem origem em fontes naturais e artificiais. Dentre as fontes naturais, as rochas da bacia de drenagem constituem a fonte básica de fosfato. Outros fatores naturais que permitem o aporte de fosfato podem ser apontados, como o material particulado presente na atmosfera e o fosfato resultante da decomposição de organismos de origem alóctone.

Determinar o estado trófico é uma ação fundamental para obtenção de informações sobre um curso de água, pois o seu conhecimento permite descrever as relações bióticas e abióticas desse ecossistema. A avaliação do estado trófico da qualidade da água é muito importante para o manejo sustentável dos recursos hídricos, e os índices utilizados, denominados índices de estado trófico (IET) foram desenvolvidos com o intuito de possibilitar a classificação das águas de corpos hídricos, facilitando, assim, informações, aos agentes de tomada de decisão e ao público, relativas ao estado ou à natureza na qual se encontram tais sistemas (OLIVEIRA et al., 2007).

Oconceito de estado tróficoémultidimensional, envolvendo aspectos de carga e transporte de nutrientes, concentração de nutrientes, produtividade e quantidade e qualidade da biota. Baseado nesse conceito foram estabelecidos índices multiparamétricos, os quais apresentaram limitada utilização em decorrência do grande número de variáveis envolvidas para seu cálculo. $\mathrm{Na}$ busca para solucionar este problema foram desenvolvidos índices com menor necessidade de variáveis, os quais resultaram na dificuldade da definição das variáveis a serem utilizadas.

Carlson (1977) desenvolveu um índice de estado trófico - IET baseado em equações que utilizam variáveis limnológicas, o qual passou a ser amplamente utilizado no monitoramento da qualidade da água em virtude da facilidade de aplicação e obtenção das variáveis de entrada no modelo.

O IET introduzido por Carlson (1977), modificado por Toledo Jr. et al. (1990), é baseado em informações relativas à biomassa fitoplanctônica presente em um determinado corpo de água, adotando-se as variáveis clorofila $a$, transparência (disco de Secchi) e fósforo total.

Desse modo, a fim de avaliar as interações entre as intervenções antrópicas e os recursos naturais da bacia hidrográfica do Rio Pomba, objetivou-se, neste trabalho,obter o Índice de Estado Trófico (IET) em nove diferentes pontos do Rio Pomba nos períodos de estiagem e chuvoso. 


\section{MATERIAL E MÉTODOS}

\section{Caracterização das áreas em estudo}

O Rio Pomba nasce nas proximidades de Barbacena-MG, na Serra do Sapateiro (ramificação da Serra da Mantiqueira), a $1.100 \mathrm{~m}$ de altitude, percorrendo cerca de $290 \mathrm{~km}$ no sentido sudeste até desaguar no Rio Paraíba do Sul, em altitude de 60 m (SANTIAGO, 1991). O trecho em estudo possui, aproximadamente, $185 \mathrm{~km}$ de extensão, abrangendo as cidades de Santa Bárbara do Tugúrio, Mercês, Rio Pomba, Guarani, Astolfo Dutra, Dona Euzébia e Cataguases (Figura 1).

Ao longo do seu percurso, o Rio Pomba recebe vários tributários, sendo os mais importantes, na margem direita, os Rios Lontra, Formoso e Novo e, na margem esquerda, os Rios Paciência, São Manoel, Paraopeba e Xopotó, além do Córrego Meia Pataca.

A área em estudo apresenta topografia acidentada, com vales estreitos e úmidos e relevo variando de fortemente ondulado a montanhoso (Mariscal-Flores, 1993). O clima regional é tropical, mesotérmico, caracterizado por verões chuvosos e brandos. A temperatura média anual é de $20,9^{\circ} \mathrm{C}$ e o índice pluviométrico médio anual é de $1237 \mathrm{~mm}$. O período mais frio corresponde aos meses de maio a agosto, sendo os dois últimos meses deste período considerados como os mais secos do ano.

\section{Amostragem}

As amostras de água do Rio Pomba foram do tipo simples, de superfície, isto é, tomadas a 0,20 a $0,30 \mathrm{~m}$ de profundidade (CETESB, 1988), na posição central da calha do rio, utilizando-se para isto embarcação. As coletas foram realizadas em quatro campanhas anuais, abrangendo períodos de estiagem (abril a setembro) e chuvoso (outubro a março), sendo efetuadas duas coletas em cada período. Foram utilizados 9 pontos para amostragem da água ao longo do trecho a ser avaliado,iniciando na nascente e finalizando a jusante da cidade de Cataguases, cujos pontos amostrados estão apresentados na Figura 2 e identificados no Quadro 1.

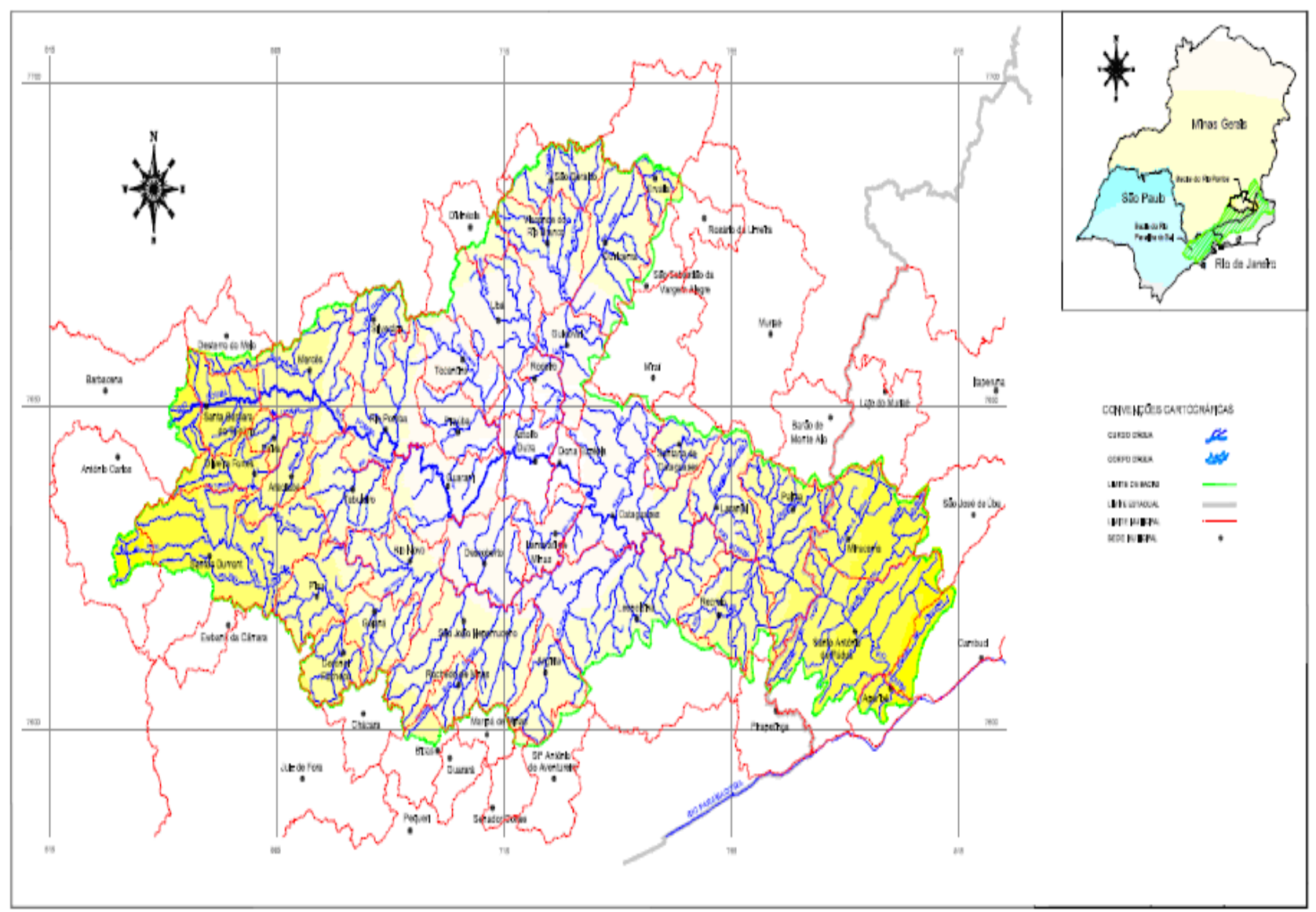

Figura 1. Bacia hidrográfica do Rio Pomba 
Quadro 1. Identificação dos pontos de coleta de amostra de água para determinação do IET no Rio Pomba

\begin{tabular}{lcccc}
\hline Ponto de coleta de amostra de água & $\begin{array}{c}\mathbf{N}^{\mathbf{0}} \mathbf{d o} \\
\text { Ponto }\end{array}$ & $\begin{array}{c}\text { Altitude } \\
(\mathbf{m})\end{array}$ & $\begin{array}{c}\text { Latitude } \\
\text { (graus) }\end{array}$ & $\begin{array}{c}\text { Longitude } \\
\text { (graus) }\end{array}$ \\
\hline Nascente do Rio Pomba & 1 & 684 & $-21,2535$ & $-43,5944$ \\
Rio Pomba à jusante de Sta. Bárbara do Tugúrio & 2 & 615 & $-21,2419$ & $-43,5370$ \\
Rio Pomba à montante do Rio Paciência & 3 & 513 & $-21,2224$ & $-43,3334$ \\
Rio Pomba à montante do Rio Lontra & 4 & 503 & $-21,2344$ & $-43,3185$ \\
Rio Pomba à montante do Rio S. Manoel & 5 & 425 & $-21,2775$ & $-43,1838$ \\
Rio Pomba à montante do Rio Xopotó & 6 & 235 & $-21,3076$ & $-42,8378$ \\
Rio Pomba à montante do Rio Novo & 7 & 195 & $-21,3775$ & $-42,7455$ \\
Rio Pomba à montante do Córrego Meia Pataca & 8 & 176 & $-21,3924$ & $-42,7455$ \\
Rio Pomba à jusante de Cataguases & 9 & 170 & $-21,4195$ & $-42,6698$ \\
\hline
\end{tabular}

\section{Bacia Hidrográfica do Rio Pomba Pontos de Coleta}

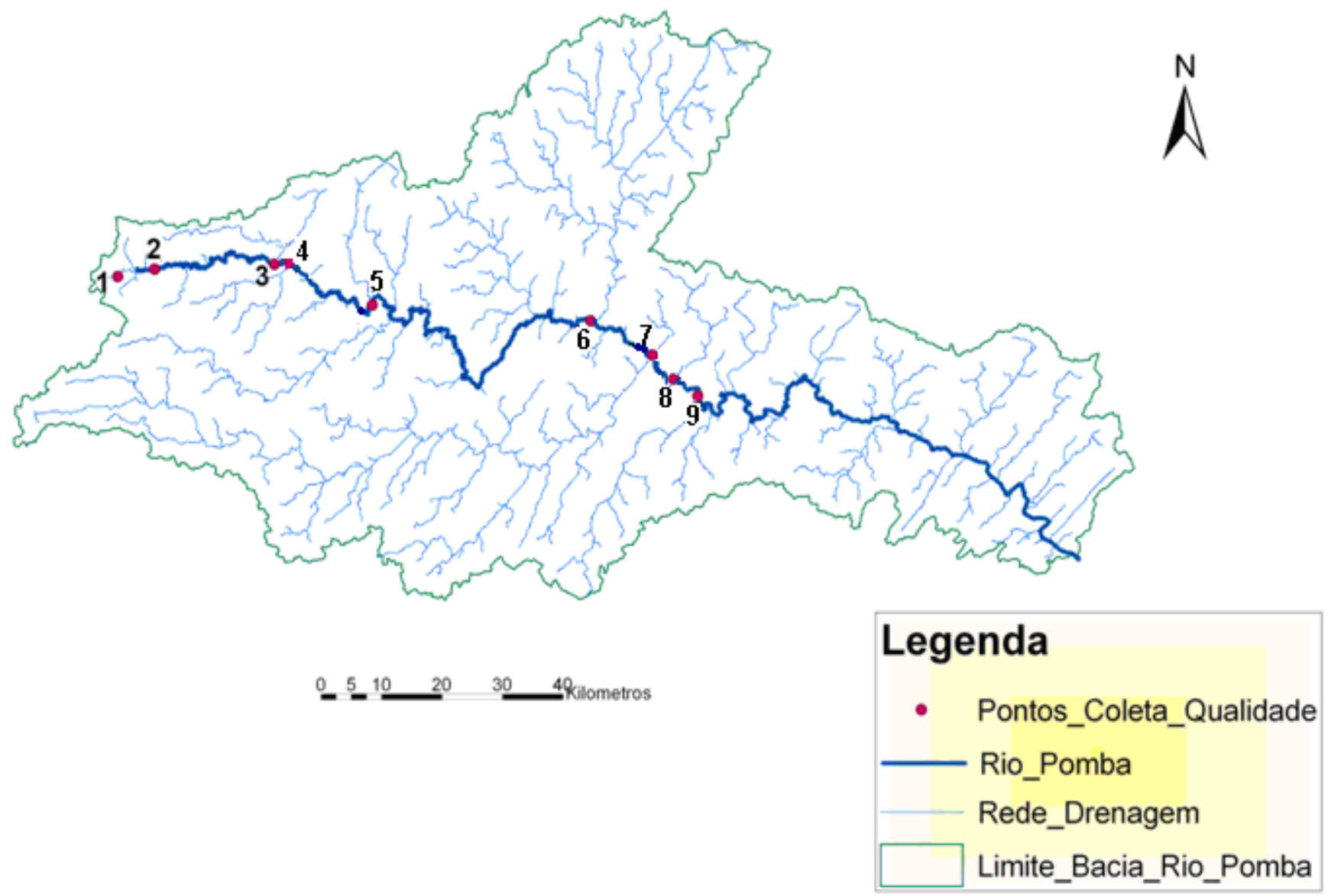

Figura 2. Localização dos pontos de amostragem de água no Rio Pomba 
As amostras foram coletadas com auxílio de uma haste metálica de $4 \mathrm{~m}$ de comprimento (extensor), na qual coletores (garrafas PET de $2 \mathrm{~L}$ ) eram fixados. Os pontos de amostragem foram selecionados de acordo com o posicionamento dos tributários mais importantes, coletando-se amostras numa distância aproximada de $100 \mathrm{~m}$ a montante das confluências. Para obtenção das coordenadas geográficas dos pontos amostrados foram georeferenciados por meio de GPS de navegação.

O fósforo total foi quantificado pelo método fósforo-molibdílico (APHA et al., 1998), realizadas no Laboratório de Qualidade da Água, do Departamento de Engenharia Agrícola, da Universidade Federal de Viçosa.

\section{Obtenção do Î́ndice de Estado trófico (IET)}

Para o cálculo do IET nos diversos pontos do Rio Pomba, utilizou-se o índice de estado trófico adotado pela CETESB, que é o introduzido por Carlson (1977) modificado por Toledo (1990), A CETESB não considera, normalmente, na estimativa de estado de trofia, o cálculo do índice de transparência, pois esta variável é afetada pela turbidez decorrente de material em suspensão, comum em corpo de água de regime lótico.

No caso de não haver resultados de clorofila a, como é a condição do presente trabalho, devido à existência de trechos com alta correnteza, turbidez e concentração de material em suspensão, dificultando a análise confiável da clorofila a, considera-se apenas a variável fósforo total, utilizando-se a Equação 1 (TOLEDO Jr. 1990).

$$
\operatorname{IET}_{\mathrm{PT}}=10\{6-[\ln (80,32 / \mathrm{PT}) / \ln 2]\}
$$

em que,

$\mathrm{IET}_{\mathrm{PT}}=$ índice de estado trófico para fósforo; e

PT = concentração de fósforo total, medida à superfície da água $\left(\mu \mathrm{g} \mathrm{L}^{-1}\right)$.
Segundo Barros (2008), em praticamente todas as classificações para o Rio Turvo Sujo a concentração de fósforo total conduz a uma classificação do ambiente em classe superior à obtida quando a clorofila a é tomada como referência. Devido às suas velocidades mais altas, em comparação aos lagos e reservatórios, normalmente os rios não conseguem manter uma densa comunidade fitoplanctônica, embora possuindo quantidades consideráveis de nitrogênio e fósforo. Portanto, para ambientes lóticos, a classificação baseada em clorofila $a$ conduz à subestimação do estado de trofia.

No Quadro 2 está apresentada a classificação trófica e a faixa de variação do IET proposta por Toledo Jr. (1990), a qual está baseada na concentração de fósforo total.

Os valores da turbidez do Rio Pomba, nos pontos em estudo, estão apresentados no Quadro 3.

\section{RESULTADOS E DISCUSSÃO}

Os valores de concentração do fósforo total e os índices de estado trófico para diferentes pontos de amostragem das águas do Rio Pomba estão apresentados no Quadro 4.

$\mathrm{O}$ valor máximo para a concentração de fósforo, observada no presente trabalho, foi de $586 \mu \mathrm{g} \mathrm{L}^{-1}$, em amostra coletada no ponto de número 5 , a jusante da confluência com o Rio Paciência (receptor dos efluentes da cidade de Mercês) que, possivelmente, se deveu aos primeiros escoamentos superficiais no início do período chuvoso, que conduziu elevada quantidade de sedimentos para o curso de água, o que pode ser confirmado pela alta turbidez (133,5 UTN), associado aos despejos de esgoto sanitário da cidade Mercês.

Segundo Lamparelli (2004), as concentrações médias dos nutrientes, sobretudo o fósforo total, são mais elevadas em ambientes lóticos $\left(193 \mu \mathrm{g} \mathrm{L}^{-1}\right)$ que em ambientes lênticos $\left(75 \mu \mathrm{g} \mathrm{L} \mathrm{L}^{-1}\right)$. No ano 2000, esse autor verificou que, dentre todos os valores das concentrações de fósforo total obtidas pela rede de monitoramento

Quadro 2. Critérios para classificação do índice de estado trófico (IET)

\begin{tabular}{ccc}
\hline Critério & Fósforo total $\left(\boldsymbol{\mu} \mathbf{g ~ L}^{-1}\right)$ & Estado trófico \\
\hline IET $\leq 24$ & $\leq 6$ & Ultraoligotrófico \\
$24<$ IET $\leq 44$ & $7,0-26,0$ & Oligotrófico \\
$44<$ IET $<54$ & $27,0-52,0$ & Mesotrófico \\
$54<$ IET $<74$ & $53,0-211,0$ & Eutrófico \\
IET $>74$ & $>211,0$ & Hipereutrófico \\
\hline
\end{tabular}

Fonte: Toledo Jr. (1990). 
do Estado de São Paulo, 85,9\% superaram o valor estabelecido na Resolução CONAMA nº 20, de 1986 (Brasil, 1986). O autor relatou que não houve diferença entre as concentrações deste elemento em períodos secos e chuvosos, para ambientes lóticos.

Observou-se que, dentre todos os valores das concentrações de fósforo total obtidas neste trabalho, apenas $47,22 \%$ ultrapassaram o padrão estabelecido na Resolução CONAMA no 357 (BRASIL, 2005) para águas de classe 1 e 2 , regime lótico, que é de $100 \mu \mathrm{g} \mathrm{L}^{-1}$. Porém, Barros (2008) observou que as concentrações de fósforo total nas águas do Rio Turvo Sujo ultrapassaram, em todos os pontos e épocas avaliadas, o limite máximo estabelecido na legislação para águas de classe 1 e 2 , regime lótico.

$\mathrm{O}$ trecho aqui considerado como parte do alto Rio Pomba, isto é, da nascente até a confluência com o Rio Paciência, apresentou valores médios para as concentrações de fósforo total de $40 \mu \mathrm{g} \mathrm{L}^{-1}$ no ponto 1 e $51 \mu \mathrm{g} \mathrm{L}^{-1}$ no ponto 2, no período de estiagem, não caracterizando estado eutrófico. Porém, a partir deste ponto, onde se inicia o aparecimento de centros urbanos mais populosos, o aumento no aporte de fósforo começou a comprometer a classificação trófica das águas do Rio Pomba, apresentando para o trecho considerado como médio Rio Pomba, valores médios para as concentrações de fósforo total iguais a $111 \mu \mathrm{g}$ $\mathrm{L}^{-1}$ no ponto 13 e $140 \mu \mathrm{g} \mathrm{L}^{-1}$ no ponto 15 , para o período de estiagem.

Já no período chuvoso, para os pontos $1 \mathrm{e} 2$, os valores médios para as concentrações de fósforo total foram de 91 e $115 \mu \mathrm{g} \mathrm{L}^{-1}$, respectivamente, e para os pontos 13 e 15 foram de 105 e $132 \mu \mathrm{g} \mathrm{L}^{-1}$, respectivamente. Segundo CHAPMAN (1992), as concentrações de fósforo, na maioria das águas naturais, encontram-se entre $5 \mu \mathrm{g} \mathrm{L}^{-1}$ e $20 \mu \mathrm{g} \mathrm{L}^{-1}$, valores bem inferiores aos determinados neste trabalho, demonstrando o grau de comprometimento imposto pelas intervenções antrópicas.

Comparando os valores de classificação do IET, segundo Toledo Jr. et al. (1990), apresentados no Quadro 3, com os valores obtidos de IET, apresentados no Quadro 4, observa-se que, no período de estiagem, o Rio Pomba encontrava-se parcialmente eutroficado, enquanto no período chuvoso, todo o percurso avaliado apresentava estado eutrófico, com faixa de variação do IET predominando entre $54 \mu \mathrm{g} \mathrm{L}^{-1}$ e $74 \mu \mathrm{g} \mathrm{L}^{-1}$.

Este aumento no aporte de $\mathrm{P}_{\text {total }}$ no corpo de água é justificável pelo mecanismo do escoamento superficial, frequentemente ocorrido nos períodos chuvosos, principalmente, em solos desprovidos de vegetação ou com predominância de cobertura rasteira $(72,63 \%$ da área amostrada da faixa de terreno compreendida pelas margens do Rio Pomba). Condição esta, que possibilita o carreamento de grandes quantidades de material de solo para os corpos de água, aumentando os valores médios das concentrações de fósforo total, que, no período de estiagem, foi de $86,61 \mu \mathrm{g} \mathrm{L}-1$ e, no período chuvoso, foi de 130,05 $\mu \mathrm{g} \mathrm{L} \mathrm{L}^{-1}$. Isso pode ser atribuído à solubilização de sais ou ao deslocamento de íons, retidos ou não às partículas de solo, carreados para o meio aquático, tal como observado por Shigaki (2006).

Quadro 3. Valores médios de turbidez obtidas no Rio Pomba em diferentes pontos de avaliação, nos períodos de estiagem e chuvoso

\section{Turbidez (UNT)}

\begin{tabular}{cccccc}
\hline \multicolumn{2}{c}{$\begin{array}{c}\text { Período de } \\
\text { estiagem }\end{array}$} & \multicolumn{2}{c}{$\begin{array}{c}\text { Período } \\
\text { chuvoso }\end{array}$} & $\begin{array}{c}\text { Média do } \\
\text { período de }\end{array}$ & $\begin{array}{c}\text { Média do } \\
\text { período } \\
\text { chuvoso }\end{array}$ \\
\cline { 1 - 4 } Ago. & Mai. & Nov. & Fev. & estiagem & chuver \\
2006 & 2007 & 2006 & 2007 & &
\end{tabular}

\begin{tabular}{clcccccc}
\hline 1 & Nascente Rio Pomba & 2,1 & 1,9 & 5,4 & 5,3 & 2,0 & 5,4 \\
\hline 2 & Rio Pomba jusante S. Bárbara do Tugúrio & 2,4 & 2,3 & 11,4 & 37,8 & 2,4 & 24,6 \\
\hline 3 & Rio Pomba montante Rio Paciência & 6,6 & 8,1 & 26,2 & 49,1 & 7,4 & 37,7 \\
\hline 4 & Rio Pomba montante Rio Lontra & 8,9 & 11,2 & 133,5 & 35,1 & 10,6 & 84,3 \\
\hline 5 & Rio Pomba montante Rio São Manoel & 11,2 & 16,8 & 31,5 & 51,8 & 14,0 & 41,7 \\
\hline 6 & Rio Pomba montante Rio Xopotó & 2,1 & 6,3 & 30,7 & 31,9 & 4,2 & 31,3 \\
\hline 7 & Rio Pomba montante do Rio Novo & 2,5 & 7,6 & 46,8 & 35,0 & 5,1 & 40,9 \\
\hline 8 & Rio Pomba montante Córrego Meia Pataca & 5,0 & 5,6 & 32,9 & 31,8 & 5,3 & 32,4 \\
\hline 9 & Rio Pomba jusante Cataguases & 10,2 & 6,9 & 32,7 & 27,1 & 8,6 & 29,9 \\
\hline
\end{tabular}


Quadro 4. Valores das concentrações de fósforo total $\left(\mathrm{P}_{\mathrm{T}}\right)$ e seus respectivos índice de estado trófico (IET) obtidos para o Rio Pomba

\begin{tabular}{|c|c|c|c|c|c|c|c|c|c|}
\hline \multirow{3}{*}{ № } & \multirow{3}{*}{ Ponto de coleta de amostra } & \multicolumn{4}{|c|}{ Período de estiagem } & \multicolumn{4}{|c|}{ Período chuvoso } \\
\hline & & \multicolumn{2}{|c|}{ Ago/2006 } & \multicolumn{2}{|c|}{ Mai/2007 } & \multicolumn{2}{|c|}{ Nov/2006 } & \multicolumn{2}{|c|}{ Fev/2007 } \\
\hline & & $P_{T}\left(\mu g L^{-1}\right)$ & IET & $P_{T}\left(\mu g L^{-1}\right)$ & IET & $P_{T}\left(\mu g L^{-1}\right)$ & IET & $P_{T}\left(\mu g L^{-1}\right)$ & IET \\
\hline 1 & Nascente Rio Pomba & 25 & 43 & 54 & 54 & 104 & 64 & 78 & 60 \\
\hline 2 & Rio Pomba a jusante de S. Bárbara Tugúrio & 52 & 54 & 50 & 53 & 144 & 68 & 86 & 61 \\
\hline 3 & Rio Pomba a montante do Rio Paciência & 68 & 58 & 108 & 64 & 118 & 66 & 104 & 64 \\
\hline 4 & Rio Pomba a montante do Rio Lontra & 89 & 61 & 43 & 51 & 586 & $\underline{89}$ & 103 & 64 \\
\hline 5 & Rio Pomba a montante do Rio São Manoel & 93 & 62 & 66 & 57 & 123 & 66 & 98 & 63 \\
\hline 6 & Rio Pomba a montante do Rio Xopotó & 67 & 57 & 80 & 60 & 78 & 60 & 76 & 59 \\
\hline 7 & Rio Pomba a montante do Rio Novo & 71 & 58 & 180 & 72 & 104 & 64 & 65 & 57 \\
\hline 8 & Rio Pomba a montante do C. Meia Pataca & 112 & 65 & 110 & 65 & 108 & 64 & 102 & 63 \\
\hline 9 & Rio Pomba a jusante de Cataguases & 182 & 72 & 98 & 63 & 156 & 70 & 108 & 64 \\
\hline
\end{tabular}

Estado Eutrófico - itálico e negrito; Estado Hipereutrófico - itálico, negrito e sublinhado.

Os centros populacionais situados às suas margens do Rio Pomba também contribuíram para aumento na concentração de fósforo. Pode ser observado no Quadro 4 que ocorreram maiores elevações deste nutriente junto maiores tendências ao aumento deste nutriente a jusante das áreas urbanizadas. Além disso, durante o período chuvoso, o escoamento superficial das áreas urbanas e rurais proporcionaram carreamento de excrementos de animais e outros materiais orgânicos destas áreas para o leito do corpo de água.

Segundo Prada \& Oliveira (2006), os sedimentos em corpos hídricos têm papel fundamental na ciclagem de nutrientes, pois a carga interna dos nutrientes proveniente desses sedimentos pode ser da mesma ordem de magnitude ou até mesmo maior que aquela advinda das entradas externas. Logo, o aumento no aporte de fósforo nas águas do Rio Pomba, no período chuvoso, pode também estar relacionado à ressuspensão dos sedimentos de fundo, com o aumento da vazão.

Rodríguez (2001) observou, ao contrário do que foi obtido neste trabalho, aumento na concentração de nutrientes nas águas no período de estiagem e atribuiu este fato ao aumento na concentração dos mesmos nas águas, devido à redução da vazão. Stacciarini (2002), avaliando a qualidade dos recursos hídricos em Paulínia - SP, observou que, na maioria dos pontos estudados, as concentrações de fósforo foram maiores no período de estiagem. Cruz (2003) chegou aos mesmos resultados, realizando trabalhos no Rio Uberaba. Avaliando o Rio Turvo Sujo, Barros (2008) encontrou maiores concentrações de fósforo total no período chuvoso. No presente trabalho, o comportamento sazonal do fósforo foi semelhante ao observado por Barros (2008), portanto, acredita-se que isso se deveu à forte influência antrópica que está sujeita a bacia do Rio Pomba.

Apesar das altas concentrações de fósforo na água, não se observou, ao longo do percurso estudado, presença de vegetação aquática no talvegue do rio, o que pode estar associado à velocidade de escoamento das águas do Rio Pomba, desfavorecendo tal formação, o que também foi observado por Gonçalves et al. (2005).

\section{CONCLUSÃO}

Diante dos resultados obtidos, pode-se concluir que:

Os valores do Índice de Estado Trófico (IET), para os diversos pontos avaliados no Rio Pomba, foram indicativos de estado de eutrofização, com tendência à hipereutrofização;

As maiores concentrações de fósforo nas águas estão associadas a trechos nos qual o Rio Pomba é receptor de grande carga de efluentes domésticos e industriais.

\section{REFERÊNCIAS BIBLIOGRÁFICAS}

\section{APHA [AMERICAN PUBLIC HEALTH ASSOCIATION]; AWWA [AMERICAN WATER WORKS ASSOCIATION]; WEF [WATER ENVIRONMENT FEDERATION]. Standard methods for the examination of water and wastewater. 20th. ed. Washington. D.C.: APHA/AWWA/WEF, 1998, [s.n.].}

BARROS F.M. Dinâmica do nitrogênio e do fósforo e estado trófico nas águas do Rio Turvo Sujo. Viçosa: UFV, 2008. $172 \mathrm{f}$. (Tese de doutorado).

BRASIL. Resolução CONAMA (Conselho Nacional de 
Meio Ambiente). Resolução no 357, de 17 de março de 2005. Dispõe sobre a classificação dos corpos de água e diretrizes ambientais para o seu enquadramento, bem como estabelece as condições e padrões de lançamento de efluentes, e dá outras providências. Diário Oficial da Republica Federativa do Brasil, Brasília, 2005.

BRASIL. Resolução CONAMA (Conselho Nacional de Meio Ambiente). Resolução ${ }^{\circ}{ }^{2} 20$, de 18 de junho de 1986. Dispõe sobre a classificação dos corpos de água e diretrizes ambientais para o seu enquadramento, bem como estabelece as condições e padrões de lançamento de efluentes, e dá outras providências. Diário Oficial da Republica Federativa do Brasil, Brasília, 1986.

CARLSON, R.E. A trophic state index for lakes. Limnology and Oceanography, v.22, p.361-369, 1977.

CAVENAGHI, A.L. Caracterização da qualidade de água e sedimento relacionados com a ocorrência de plantas aquáticas em cinco reservatórios da Bacia do rio Tietê. Botucatu: UNESP, 2003. 73f. (Tese de doutorado).

\section{CETESB (COMPANHIA DE TECNOLOGIA} AMBIENTAL DO ESTADO DE SÃO PAULO). Guia de coleta e preservação de amostras de água. São Paulo: CETESB, 1988. 160 p. (Série Relatórios).

CHAPMAN, D. Water quality assessment. A guide to the use of biota, sediments and water in environmental monitoring. 1. ed. UNESCO / WHO / UNEP. Chapman \& Hall. 585p.

CRUZ, L.B.S. Diagnóstico ambiental da bacia do Rio Uberaba, MG. Campinas: UNICAMP, 2003. 180 f. (Tese de doutorado).

ESTEVES, F.A. Fundamentos de Limnologia. 2.ed. Rio de Janeiro: Interciência, 1998. 602p.

GONÇALVES, C.S.; RHEINHEIMER, D.S.; PELLEGRINI, J.B.R.; KIST, S.L. Qualidade da água numa microbacia hidrográfica de cabeceira situada em região produtora de fumo. Revista Brasileira de Engenharia Agrícola e Ambiental, v.9, n.3, p.391-399, 2005.

LAMPARELI, M.C. Grau de trofia em corpos de água do estado de São Paulo: avaliação dos métodos de monitoramento. São Paulo: USP, 2004. 207f. (Tese de doutorado).

MARISCAL-FLORES, E.J. Potencial produtivo e alternativas de manejo sustentável de um fragmento de Mata Atlântica secundária, Município de Viçosa, Minas Gerais. Viçosa: UFV, 1993. 165f. (Dissertação de mestrado).

OLIVEIRA, G.S.; ANTUNES, F.M.; VAZ, S.S.; SILVA, A.M.; ROSA, A.H. Parâmetros físico-químicos e balanço biogeoquímico de nutrientes inorgânicos na avaliação da qualidade da água do Rio Sorocaba-SP. In: Reunião Anual da Sociedade Brasileira de Química, 30, Águas de Lindóia, 2007. Anais... Águas de Lindóia: SBQ, 2007. http://sec.sbq.org.br/cdrom/30ra/resumos/ T1251-1.pdf. 08 nov. 2007.

PRADA, S.M. ; OLIVEIRA, E. de Distribuição de nutrientes $(C, N$ e $P$ ) em testemunhos de sedimentos do reservatório das Garças, Cotia - SP, In: Reunião Anual da Sociedade Brasileira de Química, 29., 2006, São Paulo. Anais... São Paulo, 2006.

RODRIGUEZ, M.P. Avaliação da qualidade da água da bacia do Alto Jacaré-Guaçu/SP (Ribeirão do Feijão e Rio do Monjolinho) através de variáveis físicas, químicas e biológicas. São Carlos: UFSCar, 2001. 175f. (Tese de doutorado).

SANTIAGO, S.B. História do município de Rio Pomba. Síntese histórica. Belo Horizonte: Imprensa Oficial, 1991. p.63-64.

SHIGAKI, F. Transporte de fósforo na enxurrada superficial em função do tipo de fonte $P$ e intensidade das chuvas: Relevância à gerência ambiental em sistemas de produção brasileiros. Piracicaba: USP, 2006. 113f. (Tese de doutorado).

STACCIARINI, R. Avaliação da qualidade dos recursos hídricos junto ao Município de Paulínia, Estado de São Paulo, Brasil. Campinas: UNICAMP, 2002. 214f. (Tese de doutorado).

TOLEDO, Jr. A.P. Informe preliminar sobre os estudos para obtenção de um índice para avaliação simplificada do estado trófico de reservatórios de regiões quentes tropicais. Relatório técnico. CETESB, São Paulo. Outubro de 1990. 11p. 